\title{
EDITORIAL
}

\section{OPTIMISING ROLE OF DRUGS IN PATIENT CARE}

A logical approach to disease management is one that comprises both non-pharmacologic as well as pharmacologic interventions. Institution of dietary modification, weight regulation, health counselling in general, are some of the non-pharmacologic interventions which are practiced alone or in combination with use of drugs. But drugs are substances which, while conferring benefits, may also cause harm; therefore caution is needed when using them.

Optimising the role of drugs in healthcare therefore requires that before administering a drug, the healthcare provider must ask some questions pegged to basic principles of pharmacotherapy, including the following: (i) whether he should, in the first place, interfere with the patient by giving drugs? (ii) what is the exact alteration in the patient's condition that he hopes to achieve? - in other words - what is the patho-physiological alteration that he wishes to correct? (iii) is the drug to be administered capable of bringing the desired change? (iv) what other effects does the drug have, and are these effects harmful? (v) does the likelihood of benefit outweigh that of harm, in other words, the healthcare provider must consider benefit versus harm and efficacy versus safety (1). These considerations, in part, describe a phenomenon generally known as rational use of drugs or medicines. In this communication, the word "drug" is used interchangeably with the word "medicine".

Rational use of drugs is a demanding exercise because it requires that appropriate drug must be available to the people who need it at a price they can afford, and, when needed, the drug is prescribed correctly, taken by the patient in correct quantities; at the correct time intervals and for the professionally recommended time duration. Rational use of drugs also demands that the drug so prescribed and consumed by the patient is effective, of acceptable quality and safety. The concept of rational use of drugs is therefore both holistic and overtly idealistic which, in itself, prescribes a tall order - a rigid yardstick for best therapeutic practice. This subject has concerned international bodies such as the World Health Organisation over the last few decades (2).

Fulfillment of rational use of drugs presents concrete hurdles or challenges. These challenges may residein the courts of the Government, theinstitutions providing education and training to various cadres of healthcare workers involved in prescribing, dispensing and managing procurement, storage and distribution of drugs. The challenges also concern the consumer and consumer organisations, where these organisations exist, as well as the pharmaceutical industry.

The Government of the day must exhibit political will and a commitment in establishing the requisite legislation and statutory mechanisms that promote rational drug use. Such legislations must be un-ambiguous and non-contradictory of one another. In Kenya there are many health and health-related legislations, some overlapping and others occasionally conflicting. The over-arching legislation is the Public Health Act; however, with regard to drugs, there is the Pharmacy and Poisons Act - Chapter 244, Laws of Kenya. At a lower legal hierarchy, we have the national drug policy whose implementation has remained partial and wanting in many aspects. The Pharmacy and Poisons Board is established by the legal authority of Chapter 244 of the Laws of Kenya, and is responsible for many key functions, including issuance of licenses for drug outlets, such as retail pharmacies. While the pre-establishment legal requirements for these pharmacies are largely achieved, the day-to-day operation of many of them leaves a lot to be desired. Many slum areas and low-income residential places in the country are littered with sub-optimally operated pharmacies. Clearly many of them pose a danger by propagating irrational drug use. The paper by Kwena and colleagues published in this issue of the journal (3) is a point in case. This paper is based on a study that examined treatment given to self-referred individuals who presented at 50 randomly selected retail pharmacies in the Kibera slums of Nairobi. The individuals were simulated patients who offered symptoms of gonorrhoea and genital ulcer disease. It is not surprising that only $10 \%$ of these drug outlets offered treatment that was deemed appropriate with reference to Government therapy protocols for sexually transmitted diseases. Several reasons are responsible for this finding, the main one being that staff in retail pharmacies in a place like Kibera are unlikely to have been trained in diagnosis of disease and issuance of prescriptions. In such settings, the danger of drug resistance and chronic morbidity looms high.

In 1997, findings from a similar study were reported by Indalo (4). She also used simulated patients, this time university medical students with good knowledge of drugs, and examined the issue of antibiotic sale behaviour as a contributing factor to antimicrobial drug resistance. Thirty four chemists in the central business district of the City of Nairobi and ninety in the peri-urban centres were randomly 
selected and visited by the simulated patients. Sixty four per cent of the chemists sold antibiotics without prescription from doctors; most shops sold other drugs to patients directly on request, and these drugs were under dosed. From this study, it was noted that antibiotic sale behaviour in retail chemist shops in Nairobi was likely to contribute to bacterial resistance, and that sale of under dose antibiotics in non-established diagnoses would create problems due to un-eradicated infection. So where have we failed, and what needs to be done?

It is a well known fact that enacting laws is one thing, and enforcing them is another. For various reasons, the latter has not been attended to with the necessary vigour and detail with regard to drugs. Upon this background is the trade liberation that has witnessed drugs being brought into Kenya from different world sources, with strong possibility of compromising the quality, particularly in an environment without post-market surveillance.

How then do we hope to optimise the role of drugs in the Kenyan healthcare? What is the way forward? Firstly, the many health and health-related legislations should be reviewed and streamlined. This exercise should aim at rendering these legislations clear, unambiguous, non-conflicting and also stem redundancies. Secondly, the statutory bodies such as the Pharmacy and Poisons Board and the Medical Practitioners and Dentists Board should be more vigilant in their supervisory and inspectorate duties to eliminate both illegally existing and unprofessionally operated "clinics and pharmacies". This recommendation is hinged on the thesis that all is not well in the area of education and regulation of prescribers and dispensers of medicines in this country. The scenario regretfully spells a degree of anarchy in healthcare where some groups of individuals are involved in healthcare without rigid and adequate control and regulation. The groups involved in Kenyan healthcare include: medical doctors, pharmacists, clinical officers, nurses, laboratory technologists, pharmaceutical technologists, traditional health practitioners, community health workers, and unfortunately, even quacks. These groups are engaged in various aspects of healthcare, including taking histories of patients' symptoms, examining them, requesting laboratory tests, issuing prescriptions and dispensing drugs. Some of the so-called health workers do not have proper education to undertake the duties and responsibilities they have arrogated to themselves. But why do they have patronage? In my view, the answer is a simple one - these quacks are in demand because of poverty. Many slum dwellers such as those in Nairobi's Kibera area are poor, medically-ignorant and desperate-desperate about shelter, clothing, food and healthcare.

Another step in optimising the role of drugs in the Kenyan healthcare is to actively and purposefully eliminate possible corrupt practices at the various stages of quality control, registration, procurement, establishment and day-to-day management of pharmacies and other drug stores. Health professionals convicted of corrupt practices in drug-related matters should be brought to book not only according to the legal system of the country but also by the disciplinary structures of their respective regulatory bodies. Similarly, education and provision of information to the consumer and consumer organisations should be pursued as a future avenue. Elsewhere, health consumer organisations are popularly held as powerful tools for ensuring quality of drugs and service in healthcare. Unfortunately, they are few and scattered in the Kenyan scene.

Bill Lore, MD, FRCP (Edin), FRCP, RCPS (Glasg), FRCP (Lond), FACA Chair, International Network for Rational Use of Drugs - Kenya, P. O. Box 2130800505, Ngong Road, Nairobi, Kenya

\section{REFERENCES}

1. Laurence, D.R. (ed). Clinical Pharmacology. Churchill - Livingstone. Edinburgh and London

2. The Rational Use of Drugs. Report of the Conference of Experts, Nairobi: 25-29 November, 1985. World Health Organization. Geneva. 1987.

3. Kwena, Z. A., Sharma, A., Muga, C., etal. Management of simulated patients with sexually-transmitted infections by staff of retail pharmacies in the Kibera slums of Nairobi. East Afr. Med. J. 2008; 85: 419-424.

4. Indalo, A. A. Antibiotic sale behaviour in Nairobi; a contributing factor to antimicrobial drug resistance. East Afr. Med. J. 1997; 74: 171- 173. 